\title{
17. Slow Release: Multi-Generational Understandings of Two Open "Incidents" in the Closed Nuclear Files
}

\section{Robert Anderson}

Robert Anderson is a professor emeritus of communication at SFU, and is working (slowly) on a book whose working title is Negotiating Nuclear Power, focusing on the inter-play of the nuclear powers and India and Pakistan 1950-2000; or, understood another way, the uses by India and Pakistan of the nuclear "great" powers. He is author of Nucleus and Nation: International Networks, Scientists, and Power in India. University of Chicago Press 2010. randerso@sfu.ca

Unlike a young administrator or novice historian-in-training, I did not really enter the archival nuclear world on purpose. People with that kind of life and career objective would have been sent to the archives and properly guided, according to their purpose, which I suppose translates as their need to know. I was more like Alice, descending sideways down the rabbit hole into Wonderland. I clearly did not have a need to know. I do not think there was such a thing as nuclear studies in the mid-60s when I began. So I am speaking more to those socalled accidental nuclear historians who might feel awkward, like me, about their innocence and lack of preparation. I hope to inspire all of you to take the long view of your research. I reveal here how very slowly some useful information about two single nuclear decisions came to me - and by implication came to others, too. It is the slow release of information and the extreme patience required to see it which sometimes frustrates our field, particularly those for whom this cannot be a full-time activity. There are, of course, other sources of frustration like 
deliberate disinformation, but I am focusing here on the time element: the slow release of the evidence for our studies.

I am offering here my slowly evolved understanding of three separate moments in India's and Canada's nuclear history, namely the 1957 decision to mix American heavy water as the moderator in the CANDU reactor being built near Mumbai, the 1972 decision to test a nuclear explosion, and the test itself on May 18, 1974 in a Rajasthan desert in India. Those decisions were separated by seventeen years. I am writing about a series of my passive entanglements with that evidence; I'm noting it was not evidence I was actively seeking, but found nevertheless. The US heavy water was delivered to India in about 1959, and installed in 1960. The CANDU reactor went critical in 1960 and came to full power in 1963. Although the 1971 through 1972 decision in Delhi to conduct a nuclear test was a secret, neither of the other activities - not the heavy water in the reactor in which the plutonium was produced nor the bomb test in 1974 - were hidden; nor could they be.

To refer specifically to my own experience, in late May 1974, I happened to be in Ottawa visiting the International Development Research Centre. The Centre was funding the new Canadian journal called Science Reporter, and I knew the editor, David Spurgeon, slightly. He somehow knew I was about to publish a monograph which touched on Homi Bhabha and his plan to build reactors and prepare for a nuclear test in India before he died in a plane crash in 1966. The editor bumped into me in the elevator and said: "Give us an article quickly on this nuclear test in India, it will go in the next issue." 
There I was in Ottawa, drafting an article on India's very recent nuclear history and its first nuclear bomb test. I knew there would be experts in Ottawa who knew the background of the test but did not have any connection with them. I may have seen their names in writing but had no idea where to find them. They were not public figures, and some would be reluctant, if not forbidden, to talk to me. I thought that there must be essential documents in Ottawa to make a realistic assessment, but it did not occur to me to go to the National Library and Archives and knock on the door to ask to read them. I simply assumed that everything nuclear was closed up tight. Moreover, the idea that I would ever request and/or have the right to see those 1955 to 1968 files on Canada-India nuclear relations did not arise in my head. While training as an anthropologist, I had been among archival historians as friends at the University of Chicago, but I had not acquired a personal expectation that official nuclear files in archives were something one could request to read. I had worked as a research assistant in the Enrico Fermi Institute of Nuclear Studies (1965-67), surrounded by the rather professional openness of physicists (and their engineers) in a contradictory context of professional and state-managed nuclear secrecy. I was allowed to read Enrico Fermi's personal and administrative files in the institute. In the 1960s, professional historians requested and were reading sensitive files on the recent World War II or maybe the Korean War. But despite the 1971 release and publication of the secret Pentagon Papers about Vietnam by Daniel Ellsberg, such an expectation of access had not yet settled into the popular academic culture in Canada in which I was playing my novice role. 
Thus, I wrote that article for Science Reporter based on what I knew, referring to Homi Bhabha's famous 1965 statement to the New York Times that India could build and test a nuclear explosive device within eighteen months of a go-ahead. ${ }^{1}$ I doubt there was space to mention that the plutonium was produced in the Canadian reactor outside Mumbai in which US heavy water was the moderating medium. As it was going to press in October 1974, I heard from an official historian that those pre-1974 files about India and Canada relations, the ones which would have been useful to me, had been segregated and closed after the May 1974 bomb test. This was done, he said, in order to allow a new generation of professional specialists in the Departments of External Affairs and Defence to sift through them so they could understand the circumstances which led to Canada's contribution to India's capability for that bomb test, which India had promised to Canada it would not do. That capability included construction of the CANDU reactor near Mumbai, with a flow of many Indian physicists and engineers being trained through Chalk River. That form of cooperation was terminated by Canada immediately following the May 18 test.

Who knows what I might have found, had I searched in the National Archives during April 1974, just one month before that bomb test? Would anything nuclear from External Affairs or AECL or Defence have been transferred to the National Library and Archives of Canada before the May 1974 nuclear test? And if so, what? Or were all nuclear files too sensitive to release at that time?

This experience explains how slowly and accidentally I became an archive-oriented nuclear historian. About twenty-five years later, in the year 2000 , I was given my first viewing of 
those closed 1974 to 1975 files. I was starting to look for the existence of the Western Suppliers Group, which I was convinced were the 1960s ancestors to the Nuclear Suppliers Group that was formed immediately after the Indian test. There I saw my own journal article on the 1974 Indian bomb test, lying in a thick file marked "secret." It had formed an ironic part of the specialists' closed confidential resources ever since $1975 .^{2}$ Though the article itself showed just how limited anyone's understanding of the Indian situation was in 1974, my rediscovery of it also proved that at least one official person had read it and put pencil notes in the margin, before the article was put into this file and closed up for twenty-five more years!

Then, ten years after my first viewing of those closed files in Ottawa in 2000, while trawling through the State Department records in 2010 in Washington (supported by a SSHRC grant), I found the records which showed me just how long American diplomats reporting to Henry Kissinger had contrived to shield from view the fact that that particular Canadian reactor, later called CIRUS, contained and operated with US heavy water. They did not want questions raised by the Congress in Washington.

At the time of the CIRUS start-up in 1960, embassy officials of both countries had been discussing this heavy water exchange since March 1956! Canadian heavy water supplies were very heavily committed (perhaps due to a contract to supply the US reactors), so the Canadians turned quietly to US suppliers, who quietly supplied almost twenty tonnes. ${ }^{3}$ Those papers from the Nixon-Ford era showed how the State Department was told in 1974, probably by Kissinger himself, not to engage in "needless criticism" of the Indian test. It is not clear how many senior people who were involved in the 1960 delivery of US heavy water to India were still around 
Washington in 1974 and 1975. Not all nuclear history was on paper. So, official silence about the US heavy water in CIRUS was probably not hard to achieve and quite useful to the Americans at the time. ${ }^{4}$ Kissinger was not a strong opponent of nuclear proliferation anyway, and his officials probably picked that up. And we all know that during those months of late 1974, Kissinger was secretly negotiating for the creation of the Nuclear Suppliers Group, the group that was supposed to monitor the international transfer of the nuclear items which triggered concern for some members of the International Atomic Energy Agency (IAEA).

My accidental discovery in the US archives twelve years ago (2010) reminded me to look again at the Canadian files in the next year (2011), to look for the timing when Canadian officials finally confronted American leaders with the complaint that they ought to admit and announce that the CIRUS reactor at Trombay had operated on American heavy water from its beginning. Canada waited months to do this, accepting all the criticism for the 1974 test in India, annoyed by American evasiveness, waiting for the right moment. And there it was in the archived papers of Ivan Head, PM Pierre Trudeau's advisor, documents affirming that Kissinger \& Co had been avoiding this evidence after the Indian nuclear test, hoping it would go away. And that file also showed that American officials themselves had trouble in late 1974 finding the firm evidence about that heavy water installed in the Trombay reactor in 1960 . They had looked everywhere in Washington in May and June 1974 but only found the evidence eventually in a cupboard in their Delhi embassy. ${ }^{5}$

Then, in the following year of 2012, at the UK National Archives at Kew London, I learned accidentally (meaning, not looking for it) why the official British reaction to the 1974 
nuclear test was only briefly a furious objection and criticism of Canada. Behind the scenes, of course, the UK was secretly, with its allies, planning to criticize Canada for its careless handling of their safeguards in India. And then, publicly and suddenly, the UK adopted a more muted approach to the nuclear test in India. I had always wondered why. Would it be Kissinger's influence? I doubted that. But finally in 2012, at the UK National Archives, I accidentally found the long-hidden fact that a London journalist had discovered a British bomb team in Nevada on May 17, 18 or 19, 1974, a team which had just conducted one of a regular series of British underground nuclear tests. "It was decided," as they say in the passive voice, that the less said critically by Britain about the underground Indian nuclear test, the better. I did not follow up with the journalist asking when and how she was finally allowed to publish this story, but the intervention to slow this story down went right from the top, from the UK's Foreign Secretary himself to the journalist's publisher in London.

At the very same time, Britain had requested from India, earlier that month, flyover rights for the new supersonic Concorde aircraft on its planned route from London to Australia, something India had not been quite ready to approve. As a result, British indignation toward India's nuclear test quickly turned very quiet. Meanwhile in early 1975, just as the Nuclear Suppliers Group was getting started, the Canadians began to renegotiate an agreement with India to restart their nuclear relationship without telling their allies. It was only a split in the Canadian Cabinet, and not a big one, which suspended and ended those negotiations which could have led to a re-start of the nuclear relationship. 
What can we conclude from these three incidents and their ripple effects? I mean the US-Canada heavy water exchange decision, the Indian decision to do a nuclear test and the American decision to conceal their role in the reactor? I have referred to the UK-Canada relation and the US-Canada relation after the test; the Canada-India nuclear relationship was being reconstructed, although unsuccessfully. But each was revealed to me at very different times and places. I shall let you ask the questions now.

Only now do I realize that the archivists' knowledge of the nuclear files and the fractal patterns in which they are arranged is a special tacit knowledge, different for every department and agency. Archivists are trained in the systematics of these vast data sources, rather like systematic botanists trained to know the genus and species relations of plants. They can disagree learnedly about species differentiation and biotypes, usually about how big units called Record Groups are sub-divided and their records re-arranged. The tacit knowledge of archivists, built up through years of experience, has been extremely important to me, even though they must have found it difficult to explain to me. I got quite far on my own using my personal stumbling method. But without their guidance, I would never have found my way to the links between the records and thus to the moderate understanding I have acquired. ${ }^{6}$

Worse, I might never have seen these comparisons of Canadian practice with American, British, or Indian ones. You could say that I noted it at the time but only now do I really appreciate what it means, in the sense that only now do I really appreciate Bach's music. Perhaps this later kind of appreciation of these sensitive records is what being a nuclear historian really means. I say this because nuclear history really did begin only as recently as 
1939 or 1940, and the knowledge of it at that time (say, between 1940 and 1960) was supposed to be closed forever. That is why this public archival knowledge in nuclear studies is always in the form of slow release!

When I think of my occasional entanglements with 18 May 1974, a single day forty-eight years ago, I also realize that archivists of Canada, Britain, United States and India would fit that day into rather different patterns and contexts of their record systems. Even the French, Japanese, Australian, Chinese and Russian observers in India, while watching India very closely in 1974, would have different ways to accommodate the evidence which interests historians, particularly how they covered their astonished embassy's surprise. That is why I think comparative nuclear studies, across many archives and different traditions, and also using oral history, are now so much more doable and so extremely important. I am lucky I was supported by SSHRC to do this archival work in $2010-2013$, the rest was done without support for many years. So let's be thankful and protect the laws which keep those closed records preserved and those boxes arriving on the open shelf, preferably sooner than in the stories I have told here. 


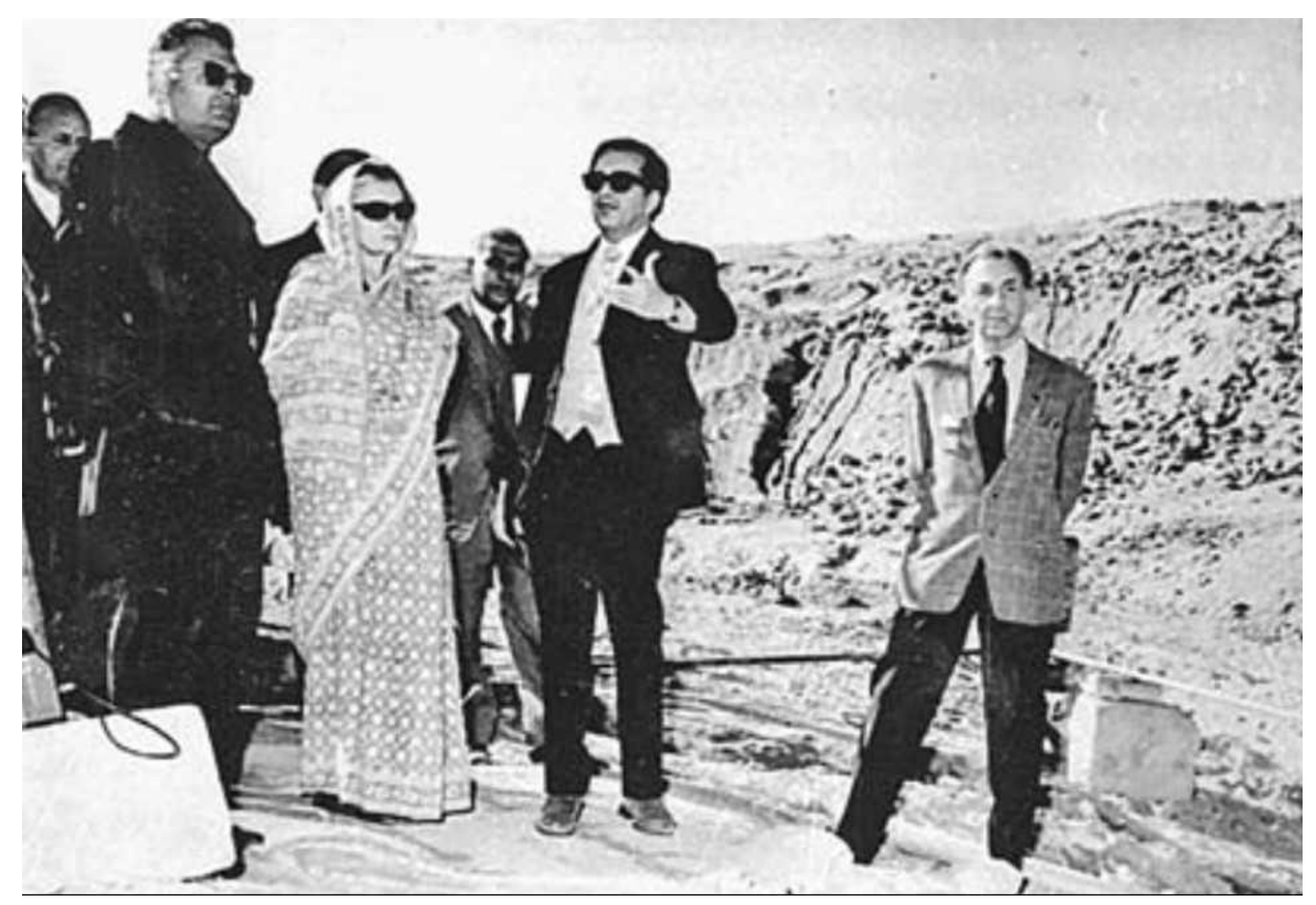

Figure 17. Standing in the radiated blast site of the single May 1974 nuclear test in the desert of Rajasthan India are some of the key actors in the drama: PM Indira Gandhi, Homi Sethna, engineer and chairman of the Atomic Energy Commission (middle, gesturing); JRD Tata, leading industrialist and member of the Atomic Energy Commission (on right, standing apart). There were very few records related to this first Indian nuclear explosion, and neither the sixty scientists and engineers involved nor the political leadership revealed the plan; the technical results of the test were not released for years. Thus, the efforts of foreign powers which included early satellite surveillance, were, despite awareness of the eventual probability of this event, unable to provide advanced detection. This photo was taken seven months after the test, in December 1974: it signaled the beginning of the end of nuclear cooperation between India, Canada, and the United States for the next thirty years. Although archival records were therefore minimal, oral history has provided a more complete understanding. How long this image had been confidential and inaccessible is unknown. (Photograph by permission of Photo Division, Ministry of Information and Broadcasting, Delhi, India, January 2009. Rights belong with Photo Division.) 
${ }^{1}$ Homi Bhabha's public announcements began in October 1964, right after the first Chinese nuclear test, and in that statement to the National Herald he said a bomb could be done in eighteen-months. Bhabha repeated that claim a year later and said India had not advanced "along that eighteen-month road". Anthony Lukas, "India Rules Out Secret Atom Test." New York Times, November 29, 1965. For the larger context see Robert Anderson Nucleus and Nation: scientists, international networks, and power in India. University of Chicago Press, 2010.

${ }^{2}$ It was published in Science Reporter (Ottawa), Winter 1974; that journal is discontinued, was not archived and is not in the National Library and Archives of Canada.

3 I speculate that the $\mathrm{H} 30$ in CIRUS was Canadian in origin but en route, under contract, to the US from the heavy water plant in Warfield near Trail, BC, a few kilometres from the border. It would be convenient, therefore, to re-label the shipment as American-origin so as not to disturb the contract. Sources are US Atomic Energy Agency, March 16, 1956, and Canadian files RG-25 Atomic Energy - Cooperation and Agreements 14003-J-2-3-40 Part 1 and 14003-J-21-40, Library and Archives of Canada, Ottawa.

${ }^{4}$ Paul Leventhal reported in 2005 that as a young staff officer for the US Senate, he was phoned on May 19, 1974 and informed by the Atomic Energy Commission that the CIRUS reactor and the Indian nuclear test had nothing officially to do with the US. If asked, he was to repeat that line. However, Leventhal became sceptical and began to investigate. Even with his special access, it took him two years "to discover that the information provided to me... was false." Source is Paul Leventhal's statement at the James Martin Center for Non-Proliferation Studies, December 19, 2005, in a statement called "CIRUS Reactor's Role in a US-India Nuclear Agreement," in the archived website of April 2007; see statement of the same name in website of "Nuclear Control Institute" at nci.org.

${ }^{5}$ The reactor had first been named the "CIR" reactor but when American heavy water was introduced it was re-named "CIRUS." Throughout the 1950s, Canada traded, via barter, materials for reactors with the US, UK, France and Norway in exchange for similar materials, often without exchange of money. In the CIRUS case, the American contribution to the CANDU reactor in 1957 was known but not publicized in the USA. I found the reference to the Ivan Head meeting in the State Department in the very well-ordered papers of Warren Christopher, deputy Secretary of State under Cyrus Vance in Jimmy Carter's Cabinet, deposited in the National Archives and Records Administration, Maryland. Ivan Head had raised the issue with Cyrus Vance in Christopher's presence. The secret burial of the US heavy water in the IndoCanadian reactor near Mumbai (which was for nuclear powers a side show) was carried out by a giant machine which wrapped nuclear matters in greater and greater secrecy, the origins of which are laid out in a new majesterial work by Alex Wellerstein, Restricted Data: the history of nuclear secrecy. University of Chicago Press, 2021. The first work I know of on this subject was written by my dissertation supervisor Edward Shils, The Torment of Secrecy. Glencoe Illinois, 
Free Press, 1956. Although there are many scholars in Canada who study secrecy and secret issues, there does not appear to be a tradition of studies such as Wellerstein.

${ }^{6}$ I was astonished when an archivist at our June 2018 workshop at the National Archives of Canada in Ottawa said casually that he had just received five kilometres of files in boxes from the unit in which he specializes, ready for cataloguing and archiving. These boxes contained millions of pages of paper. But although delivered, those boxes were not "really ready for cataloguing" he said, thus requiring much more work. At first, I thought I had misheard and/or misunderstood his statement regarding the volume of files; it seemed impossible to me that there would be five kilometres of archive boxes delivered in trucks! 